Estudios Constitucionales, Año 12, No 1, 2014, pp. 329-364.

ISSN 07180195

Centro de Estudios Constitucionales de Chile Universidad de Talca

"El valor asignado por la jurisprudencia del Tribunal Constitucional a la jurisprudencia de la

Corte Interamericana de Derechos Humanos"

Liliana Galdámez Zelada

\title{
EL VALOR ASIGNADO POR LA JURISPRUDENCIA DEL TRIBUNAL CONSTITUCIONAL A LA JURISPRUDENCIA DE LA CORTE INTERAMERICANA DE DERECHOS HUMANOS*
}

\author{
The Value assigned BY THE CASE LAW OF THE CONSTITUTIONAL \\ COURT TO THE CASE LAW OF THE INTER-AMERICAN \\ Human Rights CourT
}

\author{
LILIANA GALDÁMEZ ZELADA** \\ Universidad de Talca - Chile \\ lgaldamez@utalca.cl
}

RESUMEN: Este trabajo analiza la invocación de la jurisprudencia de la Corte Interamericana de Derechos Humanos por parte del Tribunal Constitucional de Chile, una de las obligaciones promovidas por la Corte IDH a partir del llamado control de convencionalidad. En este trabajo se dará seguimiento a estos desarrollos y se adelantarán algunas conclusiones.

ABSTRACT: This paper will examine the invocation by the Constitutional Court of Chile of the case law of the Inter-American Court of Human Rights, one of the privities advanced by the IACHR as part of the control of conventionality. This paper will follow developments and offer some conclusions.

PALABRAS CLAVE: Control de convencionalidad, Corpus iuris interamericano y su impacto en el derecho interno, Invocación de la jurisprudencia de la Corte Interamericana de Derechos Humanos por el Tribunal Constitucional de Chile.

KEY WORDS: Control of conventionality, Inter-American corpus iuris and its impact on domestic law, The invocation by the Constitutional Court of Chile of the case law of the Inter-American Court of Human Rights.

\footnotetext{
* Este trabajo se desarrolla en el marco del proyecto "Análisis de las sentencias del Tribunal Constitucional sobre utilización del Derecho Constitucional Extranjero y del Derecho Internacional de los Derechos Humanos y sus Implicancias para el Parámetro de Control de Constitucionalidad", patrocinado por el Fondo Nacional de Desarrollo Científico y Tecnólógico, Fondecyt. Trabajo recibido el 12 de noviembre de 2013 y aprobado el 19 de marzo de 2014.

** Doctora en Derecho por la Universidad de Valladolid, Licenciada en Ciencias Jurídicas y Sociales de la Universidad de Chile, Abogada. Investigadora del Centro de Estudios Constitucionales de Chile (CECOCH) y profesora de Derecho Constitucional en la Universidad de Talca.
} 


\section{INTRODUCCIÓN}

Antes adentrarme en el asunto que propongo abordar, quisiera explicar el origen de la investigación que se presentará.

El valor del Derecho Internacional de los Derechos Humanos en el ordenamiento chileno lleva siendo un tema de debate desde hace unos años en nuestro país. La polémica se ha centrado en el sentido y alcance del inciso segundo del artículo $5^{\circ}$ de la Constitución chilena. Para averiguar la incidencia de dicho derecho en la jurisprudencia del Tribunal Constitucional (en adelante también TC) se propuso un proyecto de investigación al Fondo Nacional de Investigación Científica (Fondecyt). Su objetivo general ha sido determinar "si la jurisprudencia del Tribunal Constitucional utiliza el derecho internacional de los derechos humanos y las decisiones jurisdiccionales de sus órganos de interpretación y aplicación, y de hacerlo, si con ello amplía o no el parámetro de control de constitucionalidad y el sistema de fuentes del derecho constitucional chileno".

En este trabajo se estudiará un aspecto muy específico del estudio descrito. Se trata de responder a la siguiente pregunta: ¿qué valor asigna el Tribunal Constitucional a la jurisprudencia de la Corte Interamericana de Derechos Humanos? (en adelante también Corte, Corte Interamericana o Corte IDH). Es importante enfatizar que no se estudiarán ahora las referencias al Derecho Internacional de los Derechos Humanos (en adelante también DIDH), que son bastante más frecuentes que las referencias a la doctrina de la Corte ${ }^{1}$. Me centraré en la invocación de la jurisprudencia de la Corte para establecer si su interpretación de la Convención Interamericana de Derechos Humanos (en adelante también Convención o $\mathrm{CADH}$ ) es considerada por el Tribunal Constitucional y qué valor le asigna.

Adelantando los resultados de la investigación, desde una perspectiva cuantitativa, la respuesta es que entre 2006 y 2011 el TC cita en seis casos jurisprudencia de la Corte IDH.

La escasa referencia a la doctrina de la Corte Interamericana tiene un contexto. Dicho contexto se relaciona con la polémica sobre el sentido y alcance del inciso segundo del artículo $5^{\circ}$. La norma ha dado lugar a distintas interpretaciones en la doctrina y en la jurisprudencia ordinaria y constitucional.

El inciso segundo del artículo $5^{\circ}$ contiene, en mi opinión, una cláusula de apertura al Derecho Internacional de los Derechos Humanos:

1 Nogueira, Humberto (2012), pp. 149-187. 
El ejercicio de la soberanía reconoce como limitación el respeto a los derechos esenciales que emanan de la naturaleza humana. Es deber de los órganos del Estado respetar y promover tales derechos, garantizados por esta Constitución, así como por los tratados internacionales ratificados por Chile y que se encuentren vigentes.

A partir de esta norma se construye en el ordenamiento nacional la relación del Derecho Internacional de los Derechos Humanos con el Derecho interno. ¿Cómo o de qué manera incide esta norma en la cuestión que analizamos?

En primer lugar, es más o menos claro (dejando siempre lugar a otras opiniones que pueda sostener una parte de la doctrina) que dicha norma hace referencia al catálogo de derechos con una muy clara referencia a los derechos esenciales que emanan de la naturaleza humana, contenidos en la Constitución y en tratados internacionales ratificados y vigentes como límite frente a los poderes públicos.

Por tanto, en segundo lugar, se puede afirmar que los derechos esenciales que emanan de la naturaleza humana contenidos en la Convención Americana de Derechos Humanos (tratado ratificado y vigente) son un límite al ejercicio de la soberanía.

Siguiendo con la secuencia lógica, en tercer lugar: ¡son de la misma manera obligatorios los criterios interpretativos elaborados por la Corte en relación a esos derechos? Esta pregunta tiene varias respuestas. Es la polémica más reciente que se ha desarrollado en torno al control de convencionalidad y que analizaremos más adelante.

El inciso segundo del artículo $5^{\circ}$ es la norma que conecta al derecho interno con el internacional de los derechos humanos, nada dice la Constitución sobre los criterios interpretativos elaborados por los órganos jurisdiccionales internacionales, nada ha dicho el TC sobre el valor que asigna a la doctrina de la Corte IDH.

Quienes propician el reconocimiento de la obligatoriedad de los criterios interpretativos de la Corte invocan los artículos 1, 2 y 62 No 3 de la Convención; también se invoca el Decreto No 873 de 5 de enero de 1981 que aprueba la Convención y que señala: "b) El gobierno de Chile declara que reconoce como obligatoria de pleno derecho la competencia de la Corte Interamericana de Derechos Humanos respecto de los casos relativos a la interpretación y aplicación de esta Convención de conformidad con lo que dispone su artículo 62".

Por el contrario, quienes se oponen sostienen que la Convención carece de una norma expresa que haga obligatorios los precedentes de la Corte, y que conforme la Convención de Viena sobre Derecho de los Tratados, invocando los artículos 31 y siguientes sobre interpretación, dicha tesis no puede ser defendida. Ya ana- 
lizaremos más adelante los argumentos que en este sentido se han planteado en la doctrina nacional.

Para abordar el asunto propuesto, este estudio se divide en tres apartados: el primero para analizar la polémica sobre el valor del DIDH en el ordenamiento nacional; el segundo, para aproximarnos al control de convencionalidad, sus antecedentes y definición; el tercero, para analizar los casos donde el TC ha invocado la doctrina de la Corte IDH; al final se incluye un apartado de conclusiones.

\section{LA POLÉMICA SOBRE EL VALOR DE LOS TRATADOS EN EL ORDENAMIENTO NACIONAL}

Según se ha visto, el estudio de la invocación de la doctrina de la Corte por el Tribunal Constitucional se relaciona con los derechos fundamentales, su configuración e interpretación.

Como ya adelantamos, en la jurisprudencia del Tribunal Constitucional la doctrina de la Corte Interamericana no ocupa un lugar concluyente en la construcción de sus juicios de constitucionalidad. Podemos afirmar que no es más importante que el valor que dicho tribunal asigna a la jurisprudencia y al derecho extranjero o incluso a la jurisprudencia del Tribunal Europeo de Derechos Humanos. Así, por ejemplo, entre los años 2006-2010 se cita jurisprudencia y derecho extranjero en 35 casos $^{2}$, mientras entre 2006 y 2011 se cita doctrina de la Corte IDH en 6 casos.

En el distanciamiento del TC de Chile respecto de la doctrina de la Corte, como hemos dicho, subyace un problema no resuelto en el ordenamiento nacional: el valor de los tratados internacionales sobre derechos humanos, discusión que inicia con la reforma al inciso segundo del artículo $5^{\circ}$ en $1989^{3}$. Es oportuno explicar y reforzar esta afirmación.

\footnotetext{
2 GALDÁMEZ, Liliana (2012).
}

3 Sobre este debate, se aconseja revisar Revista Ius et Praxis, Volumen 9 Número 1, año 2003. También: Andrade Geywitz, Carlos (2002), p. 111; Mohor Aguad, Salvador (1990), pp. 53-193; Medina Quiroga, Cecilia (1993); NASH Rojas, Claudio. "La Incorporación de los Instrumentos Internacionales de Derechos Humanos en el Ámbito Nacional: la Experiencia de Chile”. Compilación de la Facultad de Derecho de la Universidad de Chile (visitado el 10 de noviembre de 2008) disponible en formato electrónico: http://. cdh.uchile.cl/conferencias_charlas/Nash/Derechos_Humanos-Unicef.pdf; CEA EGAÑA, José Luis (1997), p. 81. Más recientemente se ha pronunciado también: CORREA SuTIL, Jorge: "La jerarquía de los tratados internacionales de derechos humanos luego de la reforma de 2005". Revista de Derechos Humanos, link: http://www.rdh.cl/2012/07/31/jorge-correa-sutil-la-jerarquia-normativa-de-los-tratados-internacionales-dederechos-humanos-luego-de-la-reforma-del-2005/. Consultado 4 de nov. de 2013; 
La polémica sobre el inciso 2 del artículo $5^{\circ}$ se conecta con el asunto que analizamos. Un consenso sobre el sentido y alcance de la norma permitiría definir la fuerza normativa de los derechos esenciales que emanan de la naturaleza humana y que se contienen en la CADH. Definida esta fuerza, correspondería establecer quién es el intérprete autentico de la Convención. ¿Podría el Tribunal Constitucional prescindir de la perspectiva que elabore la Corte a la hora de delimitar los derechos contenidos en la Convención? Dicho de otra manera, ¿podría el TC sostener una interpretación más restrictiva que la que es definida por la Corte? Si la fuerza de la Convención habilita el ingreso de derechos nuevos, desconectados de los contenidos en el artículo 19, entonces la opinión de la Corte sería determinante en su delimitación.

En síntesis, la ausencia de acuerdo sobre la cláusula de apertura al Derecho Internacional de los Derechos Humanos debilita la fuerza vinculante de la doctrina de la Corte Interamericana.

Podemos señalar que hoy la discusión se sitúa en dos posibles interpretaciones del inciso 2 artículo $5^{\circ}$. En la primera los tratados están sometidos al principio de supremacía constitucional ${ }^{4}$; en la segunda, se propone introducir una distinción entre el tratado y los derechos esenciales que ellos contienen, derechos que serían constitución material y desde esta perspectiva engrosarían el catálogo de derechos ${ }^{5}$.

La falta de unanimidad sobre el sentido y alcance del inciso segundo del artículo $5^{\circ}$ ha dado lugar a distintas interpretaciones en la doctrina y en la jurisprudencia de las máximas jurisdicciones. Esta polémica va a ser el escenario para que la invocación de la jurisprudencia de la Corte sea apenas apreciable en la doctrina del Tribunal Constitucional.

\section{I.1. La polémica jurisprudencial y la fuente de los derechos}

Las siguientes sentencias dan cuenta de la polémica que se ha planteado entre la jurisdicción constitucional y la ordinaria. En el caso del Tribunal Constitucional, la reciente sentencia Roles Nos. 2387 y 2388 acumulados, de 2013 dice: "Que la sola lectura de las normas contenidas en el artículo $5^{\circ}$ inciso segundo, 32 No 17 y 54 No 1 , de la Constitución chilena, que se refieren a los tratados internacionales, es suficiente para concluir que nuestro texto fundamental no

\footnotetext{
4 Sobre esta corriente Vid: Ríos, Lautaro (1998): “Jerarquía Normativa de los Tratados Internacionales sobre derechos Humanos", en Gaceta Jurídica (mayo No 215), pp. 7-14.

5 Vid GaldÁmez (2010): “Tutela judicial de graves violaciones a los derechos humanos: las actuaciones del juez y las omisiones del legislador chileno”. Estudios Constitucionales, año 8 № 2 .
} 
contiene una mención explícita al rango normativo de los tratados internacionales, ni siquiera cuando ellos versan sobre derechos esenciales que emanan de la naturaleza humana. Con todo de su contexto se infiere que los tratados internacionales tienen un rango inferior a la Constitución, porque están sometidos al control preventivo obligatorio de constitucionalidad cuando tratan materias de ley orgánica constitucional, conforme al artículo 93, inciso primero No 1 , de la Carta Fundamental, lo que no sería posible si su valor fuera igual o superior a la Constitución misma”. Considerando Duodécimo.

Por su parte, la Corte Suprema ha dicho: "(...) como lo ha señalado esta misma Corte Suprema en reiteradas sentencias, de la historia fidedigna del establecimiento de la norma constitucional contenida en el artículo $5^{\circ}$ de la Carta Fundamental, queda claramente establecido que la soberanía interna del Estado de Chile reconoce su límite en los derechos que emanan de la naturaleza humana, valores que son superiores a toda norma que puedan disponer las autoridades del Estado, incluido el propio Poder Constituyente, lo que impide sean desconocidos", Caso Molco, Considerando 22, Rol No 559-2004, sentencia de 13 de diciembre de $2006^{6}$.

En todas las cuestiones planteadas a propósito del valor de los tratados internacionales sobre derechos humanos es posible encontrar dos -o más- tesis sobre la fuente de los derechos fundamentales.

En la primera, próxima al iusnaturalismo, con el desarrollo del constitucionalismo, del Derecho Internacional de los Derechos Humanos, con la aspiración de todas las personas a un adecuado nivel de vida y a la satisfacción de sus necesidades, la búsqueda de mayor bienestar, protección del ambiente y el desarrollo sostenible, los derechos fundamentales se instalan como un deber ser, que también despierta suspicacias, un clásico en esta crítica, Bentham ${ }^{7}$, una aspiración que

6 En el mismo sentido: Caso Sandoval, Considerando Trigésimo quinto: "Que, en consecuencia, el Estado de Chile se impuso, al suscribir y ratificar los citados Convenios, la obligación de garantizar la seguridad de las personas que pudieren tener participación en conflictos armados dentro de su territorio, especialmente si fueren detenidas, quedando vedadas las medidas tendientes a amparar los agravios cometidos contra personas determinadas o lograr la impunidad de sus autores, teniendo especialmente presente que los acuerdos internacionales deben cumplirse de buena fe. Y en cuanto el Pacto persigue garantizar los derechos esenciales que nacen de la naturaleza humana, tiene aplicación preeminente, puesto que esta Corte Suprema en reiteradas sentencias ha reconocido que la soberanía interna del Estado de Chile reconoce su límite en los derechos que emanan de la naturaleza humana; valores que son superiores a toda norma que puedan disponer las autoridades del Estado, incluido el propio Poder Constituyente, lo que impide sean desconocidos".

7 J. Bentham. Anarchicall Fallacies: being and examination of the Declarations of Rights issued during the French Revolution, en Works, ed. Browring; se cita por Pérez Luño A. (1984), p. 26. 
debe satisfacerse en la mayor medida, con la mejor garantía, Carbonell (2011) ${ }^{8}$. Este es el mensaje que se ha promovido con la democracia. Es el mensaje de los jueces interamericanos, a partir del principio de progresividad, Nikken (1987) ${ }^{9}$, de los jueces europeos a través de la interpretación evolutiva de los convenios internacionales sobre derechos humanos planteada por el Tribunal Europeo de Derechos Humanos, García Roca (2012) ${ }^{10}$. Más recientemente dicha aspiración se concreta en el principio favor persona, Nogueira (2013) ${ }^{11}$. La tesis sostenida por quienes defienden una visión amplia y garantista de los derechos fundamentales se fundamenta en la búsqueda de la solución que mejor favorezca la vigencia del derecho. Así opera el principio favor persona, "un criterio hermenéutico que informa todo el derecho internacional de los derechos humanos, en virtud del cual se debe acudir a la norma más amplia, o a la interpretación más extensiva, cuando se trata de reconocer derechos protegidos, e inversamente, a la norma o a la interpretación más restringida cuando se trata de establecer restricciones permanentes al ejercicio de los derechos o su suspensión extraordinaria ${ }^{12}$.

En este sentido, se trata de buscar una interpretación armónica fundada en el artículo 29 de la Convención Americana de Derechos Humanos ${ }^{13}$ y en la Convención de Viena sobre Derecho de los Tratados, artículos 26 y 27. El catálogo de derechos es abierto, desde esta perspectiva. Su legitimación se encuentra en el

8 Vid. Nogueira, Humberto (2005) pp.15-64; Carbonell, Miguel (2011); Ávila Santa María, Ramiro (2011); UprimnY, Rodrigo (2000). "Bloque de constitucionalidad, derechos humanos y nuevo procedimiento penal” (consultado 10.10.2013). Disponible en http://www.wcl.american.edu/humright/hracademy/documents/Clase1-Lectura3BloquedeConstitucionalidad.pdf.

9 Niken (1987).

10 García Roca, Javier; Fernandez-Sanchez Pablo, Coordinadores (2009); Carrillo Salcedo, Juan Antonio (2001).

11 Vid: Nogueira, Humberto. Coordinador (2013).

12 Pinto, Mónica (1997), p. 163.

13 Art. 29 de la $\mathrm{CADH}$ "Ninguna disposición de la presente Convención puede ser interpretada en el sentido de:

a) permitir a alguno de los Estados Parte, grupo o persona, suprimir el goce y ejercicio de los derechos y libertades reconocidos en la Convención o limitarlos en mayor medida que la prevista en ella.

b) limitar el goce y ejercicio de cualquier derecho o libertad que pueda estar reconocido de acuerdo con las leyes de cualquiera de los Estados Parte o de acuerdo con otra convención en que sea parte uno de dichos Estados.

c) excluir otros derechos y garantías que son inherentes al ser humano o que se derivan de la forma democrática representativa de gobierno, y

d) excluir o limitar el efecto que puedan producir la Declaración Americana de Derechos y Deberes del Hombre y otros actos internacionales de la misma naturaleza". 
reconocimiento de la dignidad del ser humano, en la propia Constitución y en el conjunto de obligaciones adquiridas por los estados en el marco de los tratados, el ius cogens internacional, la costumbre y los principios generales del derecho, es decir, el bloque de constitucionalidad.

Por el contrario, en una tesis próxima al positivismo, se sostiene con fuerza que los derechos son los que el constituyente ha definido como posibles en un contexto económico y de desarrollo, especialmente si nos referimos a los derechos económicos, sociales y culturales. Los derechos fundamentales son el resultado del consenso, de la discusión, del equilibrio ${ }^{14}$. Los tratados internacionales ratificados y vigentes formarán parte de esos derechos, pero no de manera autónoma, Saiz Arnaíz (1999). El juez decidirá para el caso concreto cuál es el contenido del derecho, cuál prevalecerá en caso de tensiones. Pero el juez no puede inventar la norma, no puede forzar su contenido más allá de lo que razonablemente admita. Para esta tesis el legislador democrático será en definitiva el llamado a desarrollar los derechos fundamentales y el juez deberá operar en márgenes ciertos ${ }^{15}$.

Ambas tesis están presentes en el debate. Desde la perspectiva de los derechos como fruto del consenso político, será más difícil reconocer la misma naturaleza jurídica para los derechos contenidos en tratados internacionales sobre derechos humanos, precisamente porque se cuestiona su legitimidad democrática. La naturaleza de los derechos fundamentales aparecerá en la trastienda de la cuestión sobre el valor de los tratados internacionales sobre derechos humanos.

En la tesis del control de convencionalidad, estamos ante una obligación que no queda sometida a la voluntad de los Estados, veremos enseguida algunos elementos para comprender el origen de esta tesis.

Según la opinión de la Corte Interamericana, el seguimiento de su doctrina no es una cuestión que los Estados puedan libremente decidir. Se trata de una obligación oponible a todo Estado que haya reconocido su jurisdicción. Según esta tesis, las opiniones de la Corte, sea el Estado directamente condenado o no, deben ser seguidas por los tribunales nacionales y los poderes del Estado para con ello garantizar el respeto y cumplimiento de los compromisos contenidos en la Convención Americana.

\footnotetext{
14 Bobвio, Norberto (1991).

15 Una perspectiva sistémica de los derechos fundamentales en Dí́zZ-PiCAzo, Luis María (2008). Una sistematización completa en LANDA, César (2002). En la doctrina nacional sostiene esta tesis Francisco Zúñiga. ZúNIIGA, Francisco (2008).
} 
Hago presente que en este trabajo se centrará en un ámbito concreto del control de convencionalidad, según el cual, a la hora de interpretar la Convención Americana de Derechos Humanos, el juez nacional está obligado a invocar los criterios definidos por la Corte en su jurisprudencia. No estudiaremos, por tanto, todas las hipótesis en que la Corte ha considerado aplicar dicho control, sino sólo aquella que se refiere al deber de los órganos jurisdiccionales nacionales de seguir la doctrina de la Corte.

Se analizará en el siguiente apartado el origen del control de convencionalidad, su alcance y las soluciones normativas que se introdujeron en el ordenamiento mexicano para resolver los cuestionamientos al seguimiento de esta doctrina.

\section{Control DE CONVENCIONALIDAD}

\section{A) Antecedentes}

En 2004, en el sistema interamericano de protección a los derechos humanos se inició la discusión sobre los efectos de las sentencias de la Corte IDH más allá del ámbito del caso donde un Estado determinado era condenado. La carencia de esta fuerza normativa en sus sentencias restaba fortaleza al modelo regional de protección. Esta debilidad comenzó a ser atendida por la propia Corte en sus fallos y se manifestó en los informes de actividades presentados ante la Comisión de Asuntos Jurídicos y Políticos de la OEA. Esta reflexión dio lugar a un trabajo interno que involucró a la Corte y a diversos actores del sistema regional.

En este contexto, el Juez Sergio García Ramírez, en su voto razonado en el caso Tibi vs. Ecuador, reflexionó sobre el trabajo de la Corte, luego de 25 años de funcionamiento y creyó necesario impulsar su trabajo. Se refirió al "sentido" y "trascendencia" que debieran derivarse de sus resoluciones y opiniones consultivas, para en la práctica extender sus criterios más allá del caso concreto que conoce. En este sentido señaló:

"En cierto sentido, la tarea de la Corte se asemeja a la que realizan los tribunales constitucionales. Éstos examinan los actos impugnados -disposiciones de alcance general-a la luz de las normas, los principios y los valores de las leyes fundamentales. La Corte Interamericana, por su parte, analiza los actos que llegan a su conocimiento en relación con normas, principios y valores de los tratados en los que funda su competencia contenciosa. Dicho de otra manera, si los tribunales constitucionales controlan la 'constitucionalidad', el Tribunal Internacional de Derechos Humanos resuelve acerca de la 'convencionalidad' de esos actos. A través del control de constitucionalidad, los órganos internos procuran conformar la actividad del poder 
público -y eventualmente, de otros agentes sociales- al orden que entraña el Estado de Derecho en una sociedad democrática. El tribunal interamericano, por su parte, pretende conformar esa actividad al orden internacional acogido en la convención fundadora de la jurisdicción interamericana y aceptado por los Estados Parte en ejercicio de su soberanía...

Consecuentemente, en la lógica del sistema -y en las aspiraciones institucionales de la Corte Interamericana, como elemento de éste- reside la idea de que los pronunciamientos del tribunal deben trasladarse, en la forma y términos que provea el Derecho Interno -que son el puente entre el sistema internacional y el nacional-, a las leyes nacionales, a los criterios jurisdiccionales domésticos, a los programas específicos en este campo y a las acciones cotidianas que el Estado despliega en materia de derechos humanos; trasladarse, en fin, al conjunto de la experiencia nacional. Es esto -un poder de influencia, reconstrucción, orientación, información- lo que explica y justifica, a la postre, una jurisdicción internacional que no tiene la posibilidad ni la capacidad para abocarse al conocimiento de millares de juicios en los que se ventilen idénticos litigios y se reproduzcan razonamientos y pronunciamientos establecidos y reiterados con antelación" 16 .

Por otra parte, en su Informe anual de 200417, el Presidente de la Corte IDH consideró conveniente iniciar un proceso de reflexión con los órganos de la OEA, la Corte, la Comisión, Estados, Instituto Interamericano de Derechos Humanos, instituciones y representantes de la sociedad civil, académicos y observadores, que le permitiera consolidar criterios y acordar "sugerencias útiles" para "rectificar, reformar, avanzar y consolidar" en la perspectiva de iniciar una nueva etapa en su trabajo. La Comisión de Asuntos Jurídicos y Políticos de la OEA, dice el Presidente de la $\mathrm{CIDH}$, acogió esta inquietud y dio un impulso al proceso, lo que hizo posible que este debate llevara a configurar nuevas perspectivas para el trabajo de la Corte en el siglo XXI.

Así, en su balance de 2004, la Corte reconoció la creciente trascendencia de su doctrina en la "orientación de leyes, decisiones judiciales, programas administrativos y prácticas nacionales referentes a derechos humanos”18. Valoró especialmente

16 Caso Tibi vs. Ecuador, Voto Concurrente Razonado, Juez Sergio García Ramírez, párrafos: 2-3-4-5-6.

17 Correspondiente al ejercicio del año 2004, presentado ante la Comisión de Asuntos Jurídicos y Políticos de la OEA.

18 Síntesis del Informe Anual de la Corte Interamericana de Derechos Humanos correspondiente al ejercicio 2004, que se presenta a la Comisión de Asuntos Jurídicos y Políticos de la OEA, Washington, D.C., 14 de abril de 2005. 
el incremento sostenido de casos contenciosos, opiniones consultivas y medidas provisionales que llegaban a su conocimiento y lo atribuyó a "la ampliación de las expectativas" respecto a la jurisdicción americana; la introducción de nuevos asuntos más próximos a los derechos económicos, sociales y culturales, así como las reformas tanto al Reglamento de la Corte y de la Comisión.

Las conclusiones y reflexiones de la Corte en su balance de 2004 señalaron entre otras que:

a) La Corte invita a los Estados Parte a "recoger en su orden interno, de manera clara y explícita”, tanto las normas internacionales de protección a los derechos humanos como las resoluciones emitidas por sus órganos. Atribuye a este reconocimiento una enorme relevancia para la consolidación de la jurisdicción interamericana y del Derecho Internacional de los Derechos Humanos.

b) Considera el acceso a la justicia de los ciudadanos como un tema central, por lo que sugiere un sistema internacional de defensa gratuita, a semejanza de lo que ocurre en el derecho interno, a fin de asegurar a los ciudadanos el acceso a la justicia, tanto formal como material.

Sobre estas primeras consideraciones de la Corte construye el control de convencionalidad. Sus inicios se relacionan con la necesidad de crear precedentes jurídicos para los Estados Parte, que permitan que sus sentencias trasciendan el caso concreto y así su doctrina se extienda a todos los Estados Parte de la Convención Interamericana de Derechos Humanos.

\section{B) Control de convencionalidad: definición}

A partir de estas reflexiones contenidas en votos del Juez García Ramirez en los casos Mirna Mack Chang vs. Guatemala de 2003; Tibi vs. Ecuador de 2004; Vargas Areco vs. Paraguay de 2006, más adelante se produce una evolución en el caso Almonacid Arellano vs. Chile, donde el control de convencionalidad se incorpora en el cuerpo de la sentencia y es asumida por el pleno de la Corte Interamericana ${ }^{19}$.

La tesis del control de convencionalidad va desarrollándose paulatinamente y a través de su jurisprudencia la propia Corte va engrosando sus supuestos de aplicación.

En cuanto a su definición, el profesor Juan Carlos Hitters (2009) señala que "el control de convencionalidad es un mecanismo que debe ser llevado a cabo,

19 Sobre control de convencionalidad, vid además: Hitters, Juan Carlos (2009); Rey CANTOR, Ernesto (2008). 
primero por los cuerpos judiciales domésticos, haciendo una 'comparación' entre el derecho local y el supranacional, a fin de velar por el efecto útil de los instrumentos internacionales, sea que surja de los tratados, del ius cogens o de la jurisprudencia de la Corte Interamericana de Derechos Humanos; y luego esa tarea debe ser ejercida por la Corte Interamericana de Derechos Humanos si es que el caso llega a sus estrados" 20.

Veamos qué dice Eduardo Ferrer Mac-Gregor sobre su definición:

"Consiste en el examen de compatibilidad que siempre debe realizarse entre los actos y normas nacionales, y la Convención Americana sobre Derechos Humanos $(\mathrm{CADH})$, sus Protocolos adicionales, y la jurisprudencia de la Corte Interamericana de Derechos Humanos (Corte IDH), único órgano jurisdiccional del Sistema Interamericano de Protección de los Derechos Humanos, que interpreta de manera 'última' y 'definitiva' el Pacto de San José.

Se trata de un estándar 'mínimo' creado por dicho Tribunal Internacional para que en todo caso sea aplicado el corpus iuris interamericano y su jurisprudencia en los Estados nacionales que han suscrito o se han adherido a la $\mathrm{CADH}$ y con mayor intensidad a los que han reconocido la competencia contenciosa de la Corte IDH; estándar que, como veremos más adelante, las propias constituciones o la jurisprudencia nacional pueden válidamente ampliar, para que también forme parte del 'bloque de constitucionalidad/convencionalidad' otros tratados, declaraciones e instrumentos internacionales, así como informes, recomendaciones, observaciones generales y demás resoluciones de los organismos y tribunales internacionales... En realidad, lo que implica dicho 'control' es la obligación de todos los jueces nacionales (como parte del Estado) de ejercerlo, de oficio, dentro del ámbito de sus respectivas competencias y regulaciones procesales. La Corte IDH no puede (ni lo ha pretendido) convertirse en un órgano que 'defina' o 'imponga' los sistemas de control constitucional que cada país adopta, como resultado de su propia cultura, realidad y contexto histórico"21.

La definición anterior va siendo superada y ampliada por la propia Corte Interamericana en el Caso Gelman vs. Uruguay en supervisión de cumplimiento de la sentencia de 20 de marzo de 2013 (en adelante Gelman 2)22. En esta sen-

20 Hitters (2009), p. 124.

21 Ferrer Mac-Gregor, Eduardo (2011), p. 531.

22 La sentencia que comento merece una revisión, ya que en ella la Corte analiza cuál ha sido la recepción del control de convencionalidad en varios países de la región. Sistematiza, entonces, los criterios de las más altas Cortes de Argentina. Colombia, Bolivia, Perú, Guatemala, México, República Dominicana, Costa Rica y Panamá, entre otras. Para estos efectos, se sugiere revisar considerandos 75 a 86. Dichas invocaciones 
tencia, la Corte incorpora nuevos elementos y distingue dos modalidades para dicho control:

“(...) es posible observar dos manifestaciones distintas de esa obligación de los Estados de ejercer el control de convencionalidad, dependiendo de si la Sentencia ha sido dictada en un caso en el cual el Estado ha sido parte o no. Lo anterior debido a que la norma convencional interpretada y aplicada adquiere distinta vinculación dependiendo si el Estado fue parte material o no en el proceso internacional...

En relación con la primera manifestación, cuando existe una sentencia internacional dictada con carácter de cosa juzgada respecto de un Estado que ha sido parte en el caso sometido a la jurisdicción de la Corte Interamericana, todos sus órganos, incluidos sus jueces y órganos vinculados a la administración de justicia, también están sometidos al tratado y a la sentencia de este Tribunal, lo cual les obliga a velar para que los efectos de las disposiciones de la Convención y, consecuentemente, las decisiones de la Corte Interamericana, no se vean mermados por la aplicación de normas contrarias a su objeto y fin o por decisiones judiciales o administrativas que hagan ilusorio el cumplimiento total o parcial de la sentencia. Es decir, en este supuesto, se está en presencia de cosa juzgada internacional, en razón de lo cual el Estado está obligado a cumplir y aplicar la sentencia...

Respecto de la segunda manifestación del control de convencionalidad, en situaciones y casos en que el Estado concernido no ha sido parte en el proceso internacional en que fue establecida determinada jurisprudencia, por el solo hecho de ser Parte en la Convención Americana, todas sus autoridades públicas y todos sus órganos, incluidas las instancias democráticas, jueces y demás órganos vinculados a la administración de justicia en todos los niveles, están obligados por el tratado, por lo cual deben ejercer, en el marco de sus respectivas competencias y de las regulaciones procesales correspondientes, un control de convencionalidad tanto en la emisión y aplicación de normas, en cuanto a su validez y compatibilidad con la Convención, como en la determinación, juzgamiento y resolución de situaciones particulares y casos concretos, teniendo en cuenta el propio tratado y, según corresponda, los precedentes o lineamientos jurisprudenciales de la Corte Interamericana”23.

son un claro ejemplo de los diálogos multinivel y desde esta perspectiva van en la dirección de la creación de un Derecho común.

23 En este sentido señala la sentencia: "La obligación de cumplir lo dispuesto en las decisiones del Tribunal corresponde a un principio básico del derecho sobre la responsabilidad internacional del Estado, respaldado por la jurisprudencia internacional, según el cual los Estados deben acatar el tratado internacional de buena fe (pacta sunt servanda) y, como ya ha señalado esta Corte y lo dispone el artículo 27 de la Convención de Viena sobre el Derecho de los Tratados de 1969, aquellos no pueden, por razones de orden interno, dejar de asumir la responsabilidad internacional ya establecida. Las obligaciones convencionales de los Estados Parte 
Hecha esta aclaración, la Corte considera que al control de convencionalidad están obligados no sólo los jueces sino todas las autoridades estatales que deben ejercerlo de oficio. Dicho control se ejerce considerando no sólo la CADH sino también la interpretación que del mismo ha hecho la propia Corte:

“(...) todas la autoridades estatales están en la obligación de ejercer ex officio un 'control de convencionalidad' entre las normas internas y la Convención Americana, en el marco de sus respectivas competencias y de las regulaciones procesales correspondientes. En esta tarea, deben tener en cuenta no solamente el tratado, sino también la interpretación que del mismo ha hecho la Corte Interamericana, intérprete última de la Convención Americana...”.

En definitiva, para la Corte el control de convencionalidad es:

“(...) una obligación propia de todo poder, órgano o autoridad del Estado Parte en la Convención, los cuales deben, en el marco de sus respectivas competencias y de las regulaciones procesales correspondientes [deben], controlar que los derechos humanos de las personas sometidas a su jurisdicción sean respetados y garantizados. Así adquiere sentido el mecanismo convencional, el cual obliga a todos los jueces y órganos judiciales a prevenir potenciales violaciones a derechos humanos, las cuales deben solucionarse a nivel interno teniendo en cuenta las interpretaciones de la Corte Interamericana y, sólo en caso contrario, pueden ser considerados por ésta, en cuyo supuesto ejercerá un control complementario de convencionalidad" 24 .

Como queda de manifiesto en esta sentencia, al control de convencionalidad estarían obligados jueces y todos los poderes del Estado, cada uno en el ámbito de sus competencias. Se trata de una perspectiva que evidentemente amplía dicho control y que dicho sea de paso, pone al Estado chileno en una incómoda posición, dado que a la fecha el D.L. de Amnistía No 2.191 sigue vigente no obstante no es aplicado ya por el Poder Judicial ${ }^{25}$.

El control de convencionalidad es un concepto dinámico, progresivamente desarrollado por la Corte. Ya veremos de qué manera el dinamismo de esta no-

vinculan a todos los poderes y órganos del Estado, es decir, que todos los poderes del Estado (Ejecutivo, Legislativo, Judicial, u otras ramas del poder público) y otras autoridades públicas o estatales, de cualquier nivel, incluyendo a los más altos tribunales de justicia de los mismos, tienen el deber de cumplir de buena fe con el derecho internacional...”.

24 Gelman 2, Considerando 72.

25 Sobre cumplimiento de las sentencias de la Corte Interamericana de Derechos Humanos en los casos donde Chile ha sido condenado, vid: Ivanschitz Boudeguer, Bárbara. (2013), pp. 275-332. 
ción, unido a la polémica sobre el valor de los tratados sobre derechos humanos inciden para que en la jurisdicción constitucional dicho control no tenga un seguimiento sistemático, de hecho, en Gelman 2 se hace un recorrido por varias jurisdicciones latinoamericanas que han incorporado el control de convencionalidad pero, naturalmente, no se cita jurisprudencia de los tribunales chilenos en esta materia, ni tampoco de Brasil, en ambos casos debido a la resistencia de sus jurisdicciones en su aplicación.

En cuanto al futuro del control de convencionalidad, advierte Sagüés (2010) que ello dependerá de dos factores: por una parte de la aplicación prudente y sensata que haga la Corte, es decir, antes de declarar la inconvencionalidad de una norma deberá buscar una interpretación conforme, una suerte de "presunción de convencionalidad" y, por otra parte, estará condicionado a la voluntad de seguimiento de la doctrina del control de convencionalidad por parte de los tribunales nacionales ${ }^{26}$.

Merece la pena tener presentes las prevenciones que plantea Sagüés por su pertinencia y porque seguramente incidirán en los criterios que los jueces nacionales sigan desarrollando en esta materia.

\section{C) Violaciones graves a los derechos humanos: contexto para entender el control de convencionalidad}

De la abundante doctrina, a propósito del control de convencionalidad, quisiera referirme al trabajo de Laurence Burgorgue-Larsen, que plantea una perspectiva que comparto y contribuye a comprender el contexto en el que se inicia la tesis del control de convencionalidad ${ }^{27}$. Dice Burgorgue-Larsen que es en la erradicación de la impunidad donde se encuentran las claves para comprender la política jurisprudencial de la Corte IDH.

La Corte construye, en relación a graves violaciones a los derechos humanos, patrones institucionales de comportamiento. Dichos patrones se refieren tanto a las circunstancias que rodean su comisión como la impunidad que acompaña a dichos crímenes. El Estado juega un rol central, primero cometiendo o facilitando la comisión del delito en el contexto de lo que Kai Ambos llama la "macrocriminalidad" y facilitando los medios con que cuenta el Estado para garantizar la impunidad fáctica y jurídica a través de las leyes de amnistía y punto final.

26 SAGÜÉs 2010 (a), p. 131.

27 En Ferrer Mac-Gregor, Eduardo. Coordinador (2012). 
Este contexto es el que estimula a la Corte a introducir en sus sentencias reflexiones acerca de dichos patrones y las fórmulas más eficaces para poner freno a los obstáculos para la investigación y sanción de los crímenes.

Si se pudiera hacer un diagnóstico, es en materia de impunidad donde el control de convencionalidad se ha extendido con mayor fuerza y eficacia en la región. Efectivamente, por ejemplo en el caso chileno, los jueces han invocado las Convenciones de Ginebra, la Convención sobre Imprescriptibilidad de los Crímenes de Guerra y de Lesa Humanidad, Pacto Internacional de Derechos Civiles y Políticos, Convención de Naciones Unidas contra la Tortura, Declaración Americana de Derechos Humanos ${ }^{28}$.

Esta es la experiencia más extendida del control de convencionalidad no sólo en Chile sino en toda la región. En este sentido, dice Burgorgue-Larsen que la preeminencia del Derecho Internacional en la región "vale incluso sobre los mecanismos de democracia directa, i.e. incluso sobre la opinión del pueblo. Después del legislador, el pueblo también puede 'actuar mal' ignorando las exigencias del Derecho Internacional de los Derechos Humanos. No obstante, la justicia inherente a la lucha contra la impunidad debe vencer los deseos del pueblo en busca de una serenidad democrática falaz por ser amnésica, y eso, por largo que sea el paso del tiempo. Tal política jurisprudencial suscita muchas controversias y discusiones, y algunas han llegado a metamorfosearse en rechazos... Paralelamente a esta aniquilación judicial de las políticas de impunidad, era necesario que la Corte pudiera imponer a los Estados la obligación de perseguir a los autores de violaciones masivas de Derechos Humanos con el fin de que éstos pudieran ser debidamente sancionados. Esta obligación, la Corte la ha sacado a partir de los informes de la Comisión Interamericana que se fundamentaban en el derecho de las víctimas y sus familiares a la verdad..."29.

La pregunta que cabe es si puede extenderse la doctrina de la Corte a otros derechos humanos contenidos en la Convención. Extender la doctrina de la Corte supone que efectivamente se construye un derecho común, un corpus iuris interamericano, Sagües $(2010)^{30}$, espacio común que ha ido progresando en la región, pero que en comparación con el sistema europeo de protección a los derechos humanos, no va de la mano de un proceso de integración como el que se vive en Europa, Biglino (1997).

28 Sobre esta cuestión: GaldÁmeZ Zelada, Liliana (2011).

29 Ferrer Mac-Gregor, Eduardo. Coordinador (2012), p. 47.

30 También, Nogueira (2012). 
Para el caso europeo, afirma Sagüés (2010) que antes que el Tribunal Europeo de Derechos Humanos ha sido el Tribunal de Justicia de la Unión Europea el que ha sostenido con más protagonismo e intensidad la necesidad de que los jueces nacionales inapliquen el Derecho interno cuando éste contraviene el Derecho de la Unión, y que se expresa claramente en el caso Simmenthal. Por su parte, el Tribunal Europeo de Derechos Humanos ha desarrollado una versión más ligera del control de convencionalidad, ya que lo aplica pero no impone a los Estados que inapliquen el Derecho interno contrario al Convenio Europeo de Derechos Humanos.

Las particularidades que acabamos de señalar son determinantes para que jurisdicciones como las de Chile o Brasil mantengan distancia y prudencia-resistencia, respecto al control de convencionalidad.

\section{D) Un caso particular: el caso de México}

Parece necesario revisar cómo ha evolucionado el control de convencionalidad en México, donde la reforma constitucional de 2011 dio paso al desarrollo de una doctrina sobre el control de convencionalidad, a diferencia del caso chileno, donde no se cuenta con una nueva norma en esta materia.

Ferrer Mac-Gregor señala que la obligatoriedad del control difuso de convencionalidad en México se debe a: "(i) a las cuatro sentencias condenatorias al Estado mexicano (2009-2010) donde expresamente refieren a este 'deber' por parte de los jueces y órganos vinculados a la administración de justicia, en todos los niveles, para ejercerlo; (ii) a lo dispuesto en los artículos $1^{\circ}$ (obligación de respetar derechos), $2^{\circ}$ (deber de adoptar disposiciones de Derecho Interno) y 29 (normas de interpretación más favorables) de la $\mathrm{CADH}$, vigente en nuestro país desde 24 de marzo de 1981; (iii) a lo dispuesto en los arts. 26 (Pacta sunt servanda) y 27 (no invocación del Derecho Interno como incumplimiento del tratado) del Convenio de Viena sobre Derecho de los Tratados (1969) vigente en nuestro país desde el 27 de enero de 1980, (iv) a la reforma constitucional en materia de Derechos Humanos, vigente desde el 11 de junio de 2011, particularmente a los nuevos contenidos normativos previstos en el art. $1^{\circ}$ constitucional; y (v) a la aceptación 'expresa' de este tipo de control por la Corte Suprema de Justicia de la Nación, como parte importante del cumplimiento de la sentencia de la Corte IDH en el caso 'Radilla Pacheco', al conocer del expediente... lo cual implicó, entre otras cuestiones, aceptar también el 'Control Difuso 
de Constitucionalidad', al realizar una nueva interpretación del artículo 133 constitucional a la luz del vigente artículo $1^{\circ}$ del mismo texto fundamental" 31 . En el caso mexicano ha sido fundamental la reforma constitucional al artículo $1^{\circ}$ de la Constitución, que señala:

"Artículo $1^{\circ}$. En los Estados Unidos Mexicanos todas las personas gozarán de los derechos humanos reconocidos en esta Constitución y en los tratados internacionales de los que el Estado Mexicano sea parte, así como de las garantías para su protección, cuyo ejercicio no podrá restringirse ni suspenderse, salvo en los casos y bajo las condiciones que esta Constitución establece.

Las normas relativas a los derechos humanos se interpretarán de conformidad con esta Constitución y con los tratados internacionales de la materia favoreciendo en todo tiempo a las personas la protección más amplia.

Todas las autoridades, en el ámbito de sus competencias, tienen la obligación de promover, respetar, proteger y garantizar los derechos humanos de conformidad con los principios de universalidad, interdependencia, indivisibilidad y progresividad. En consecuencia, el Estado deberá prevenir, investigar, sancionar y reparar las violaciones a los derechos humanos, en los términos que establezca la ley"32.

Como puede apreciarse, para el caso mexicano el progreso del control de convencionalidad se sostiene sobre la base de la reforma de 2011. La cláusula de interpretación conforme los tratados internacionales abre la puerta para que en esta interpretación sean considerados los criterios de la Corte Interamericana.

31 Ferrer Mac-Gregor, Eduardo (2012), p. 109.

32 En este sentido señala Ferrer Mac Gregor que "La cláusula contiene un 'principio de armonización' entre la Constitución y el tratado internacional. Lo anterior significa que el intérprete debe procurar una interpretación que permita 'armonizar' la 'norma nacional y la internacional'. No se trata de dos interpretaciones sucesivas (primero la interpretación conforme a la Constitución y luego la interpretación conforme al tratado internacional), sino de una interpretación conforme que armonice ambas. Cuando la fórmula constitucional se refiere a que las normas de derechos humanos se interpretarán 'de conformidad con' 'esta Constitución y con los tratados internacionales...', la conjunción 'y' gramaticalmente constituye una 'conjunción copulativa' que sirve para reunir en una sola unidad funcional dos o más elementos homogéneos al indicar su adición. De ahí que esta cláusula cumple con una 'función hermenéutica' de armonización. Y entre las posibles interpretaciones conformes de armonización, el intérprete deberá optar por la protección más amplia. En todo caso, ante una eventual antinomia debe aplicarse la norma que favorezca 'a las personas la protección más amplia’ como solución interpretativa que la parte final de la cláusula establece; de ahí que podría prevalecer la norma nacional en términos del artículo 29.b) de la CADH”. Ferrer Mac-Gregor (2013), p. 555. 
III. La INVOCACIÓN DE LA JURISPRUdENCIA DE LA CORTE IDH POR EL Tribunal Constitucional de Chile años 2006-2011

\section{A) Estudio de casos}

Los casos en que el Tribunal Constitucional invoca jurisprudencia de la Corte Interamericana en sus fallos se pueden resumir en 6 (2006-2011). Mientras en el mismo período las referencias a jurisprudencia de otros tribunales se producen en 35 sentencias.

Entre los años 2006 y 2011 el Tribunal Constitucional dictó un total de 968 sentencias, de todas ellas sólo en 6 casos mencionó jurisprudencia de la Corte Interamericana.

Los casos en que se invoca jurisprudencia de la Corte IDH son los siguientes:

1. Rol No 567 de 2010. Movimiento Patria Nueva, sentencia de 2 de junio de 2010.

En este caso un grupo de senadores y diputados del Congreso Nacional junto al Alcalde de la comuna de la Granja y un grupo de organizaciones sociales recurren ante el Tribunal Constitucional para que declare la inconstitucionalidad de los movimientos: Patria Nueva Sociedad, Instituto de Metapolítica NS, Vanguardia Nacional Chilena, Martillo del Sur, Camisas Pardas, Estandarte Hitleriano, Movimiento Nacional Socialista de los Trabajadores, Patriotas, Juventud Nacionalista Obrera, Chile Imperial y Nueva Unión. El fundamento de este requerimiento reside en que los movimientos señalados tienen inspiración fascista y nazista, que incitan al odio y la discriminación. Posteriormente los requirentes limitan la solicitud a la declaración de inconstitucionalidad del Movimiento Patria Nueva Sociedad por su amplitud e influencia en la vida política y social del país. Los requirentes solicitan se declare su inconstitucionalidad por contravenir el artículo $19 \mathrm{No}_{\text {s. }}$ 1, 2, 12, 15.

Para elaborar su juicio de constitucionalidad, el TC recurre al Tribunal Europeo de Derechos Humanos, en adelante TEDH, en dos reclamos contra Turquía, en el caso del Partido Comunista Unificado y el partido de la prosperidad Refah. En estos casos el TEDH, dice el Tribunal Constitucional, busca establecer un equilibrio entre la defensa de la democracia y la salvaguardia de los derechos individuales. Analiza el TC la historia del antiguo artículo $8^{\circ}$, la reforma constitucional de 1989. Considera que la democracia sólo puede existir en la medida que se garantiza el pluralismo político (considerando vigésimo segundo); invoca al Tribunal Constitucional español en su manera de comprender dicho pluralismo. El TC considera que la libertad de asociación se relaciona estrechamente 
con la libertad de conciencia, de expresión, el derecho de reunión y el derecho de presentar peticiones ante la autoridad, que deben ser ponderados por el Tribunal (considerando vigésimo quinto). Asimismo, invoca los criterios del TEDH en esta materia. Enseguida el Tribunal recurre a la doctrina y a la jurisprudencia del Tribunal Constitucional español.

En lo que nos interesa ahora, la sentencia señala:

“Trigésimo quinto: Que la Corte Interamericana de Derechos Humanos ha señalado que la libertad de expresión es un medio para el intercambio de ideas e informaciones entre personas, por lo que comprende además el derecho a comunicar, el derecho a conocer opiniones, relatos y noticias; señalando que el derecho a conocer la información y opinión ajena tiene tanta importancia como el derecho a difundir la propia (Caso Palamara Iribarne, sentencia de 22 de noviembre de 2005, p. 73).

Cuadragésimo primero. Que estas normas afectan, ciertamente, a las organizaciones sociales y políticas que incurran en tales conductas según sea la legislación del país. $\mathrm{Al}$ respecto la Corte Interamericana de Derechos Humanos ha exhortado a 'que en la elaboración de los tipos penales es preciso utilizar términos estrictos, unívocos, que acoten claramente las conductas punibles, dando pleno sentido al principio de legalidad penal' (caso Castillo Petruzzi y otros, p. 121)".

Cabe señalar que el Tribunal rechaza la declaración de inconstitucionalidad por considerar que no se han reunido pruebas suficientes de la actividad ilícita del Movimiento Patria Nueva Sociedad.

Llama la atención en esta sentencia que pese a la invocación de dos sentencias de la Corte IDH, el Tribunal cita recurrentemente los fallos del Tribunal Europeo de Derechos Humanos y al Tribunal Constitucional español, no siendo determinantes los casos conocidos y fallados por la Corte IDH, recurriéndose a su jurisprudencia en la medida que refuerza los criterios del Tribunal y de ninguna manera reconociendo en ellos fuerza o autoridad sobre el juicio definitivo del TC, sin tampoco plantear ninguna clase de mención a esta cuestión ni aun en el caso Palamara Iribarne vs. Chile, donde nuestro país fue condenado.

La jurisprudencia de la Corte no es determinante para este caso, ya que se invoca junto a otros antecedentes como uno más y sin una fuerza superior a los otros argumentos presentados en la sentencia. Es en este sentido obiter dicta.

2. Rol No 1723-10 INA/1800-10 INA, acumulados sentencia de 21 de junio de 2011 .

En este caso los requirentes presentan un recurso de inaplicabilidad por inconstitucionalidad del artículo 10 letra h de la Ley No 20.285 sobre acceso a la 
información pública en proceso por reclamo de ilegalidad caratulado "Televisión Nacional de Chile con Consejo para la Transparencia”. En este caso, la inaplicabilidad se solicita ante una resolución del Consejo para la Transparencia que ordena informar sobre remuneraciones y otros beneficios que recibían funcionarios y ejecutivos del canal. Los requirentes aducen que la resolución del Consejo afecta su derecho a la vida privada contenida en el artículo 19 No 4 de la Constitución.

Para el desarrollo de su juicio de constitucionalidad el TC recurre a la doctrina, a un conjunto de disposiciones en la materia, a la Carta Democrática Interamericana. Mientras la cita de la Corte IDH señala:

“Decimocuarto. Al respecto la Corte Interamericana de Derechos Humanos ha señalado que 'el actuar del Estado debe encontrarse regido por los principios de publicidad y transparencia en la gestión pública, lo que hace posible que las personas que se encuentran bajo su jurisdicción ejerzan el control democrático de las gestiones estatales, de forma tal que puedan cuestionar, indagar y considerar si se está dando un adecuado cumplimiento de las funciones públicas' (Corte IDh, caso Claude Reyes y otros, de 19 de septiembre de 2006)".

En este caso el TC rechaza la declaración de inaplicabilidad y, como en el caso anterior, la jurisprudencia de la Corte es uno más de los antecedentes tenidos en cuenta a la hora de elaborar el juicio de constitucionalidad, refuerza su decisión pero no es su fundamento. El hecho de ser una sentencia condenatoria para Chile tampoco implica una atención especial por parte del Tribunal sino que se trata simplemente de reforzar sus argumentos sin reconocer ninguna autoridad especial a la mencionada condena.

\section{Rol $N^{o} 740$, sentencia de 18 de abril de 2008.}

Analizaremos enseguida el caso conocido como de la "píldora del día después". Un grupo de parlamentarios solicita se declare la inconstitucionalidad de parte de las normas del D.S. No 48 que regula la distribución gratuita de la píldora del día después en consultorios públicos. Para elaborar su resolución, el Tribunal tiene presente un conjunto de informes técnicos y científicos sobre el impacto del componente levonogestrel en la vida del nasciturus. Recurre también al derecho comparado, a la doctrina, al Derecho Internacional de los Derechos Humanos ${ }^{33}$

\footnotetext{
33 “(...) en la misma línea argumental, debe recordarse que la Convención Americana de Derechos Humanos -tratado internacional ratificado por Chile y que se encuentra vigente- señala, en su artículo 4.1, que: "Toda persona tiene derecho a que se respete su vida. Este derecho estará protegido por la ley y en general, a partir del momento de la concepción. Nadie puede ser privado de la vida arbitrariamente". De esta manera, este tratado internacional -que forma parte del ordenamiento jurídico chileno- resalta que todo ser humano
} 
y especialmente al invocar el principio favor persona, ya que considera que, ante la duda de los efectos concretos del componente aludido en la vida del no nacido, opta por su prohibición, ya que ignora si efectivamente se afectará la vida del que está por nacer, de allí que opta por una protección preventiva del derecho a la vida.

"Que, para dilucidar el conflicto constitucional planteado y ante la evidencia de estar estos jueces frente a una duda razonable, ha de acudirse a aquellos criterios hermenéuticos desarrollados por la teoría de los derechos fundamentales, por ser ésa la materia comprometida en el presente requerimiento. En tal sentido, parece ineludible tener presente el principio 'pro-homine' o 'favor libertatis' definido en la jurisprudencia de la Corte Interamericana de Derechos Humanos de la siguiente forma: 'Entre diversas opciones se ha de escoger la que restringe en menor escala el derecho protegido (...) debe prevalecer la norma más favorable a la persona humana' (Opinión Consultiva 5, 1985)... Que de todo lo expuesto sólo es posible concluir que la existencia de una norma reglamentaria que contiene disposiciones que pueden llevar a afectar la protección del derecho a la vida de la persona que está por nacer y que la Constitución buscó cautelar especialmente, la vulnera porque la sola duda razonable, reflejada en las posiciones encontradas de los expertos del mundo de la ciencia, de que la aplicación de esas normas reglamentarias pueda llegar a afectar el derecho a la vida del nasciturus, obliga al juez constitucional a aplicar el principio 'favor persona' o 'pro-homine' en forma consecuente con el deber impuesto al Estado por la Carta Fundamental de estar al 'servicio de la persona humana' y de limitar el ejercicio de la soberanía en función del respeto irrestricto del derecho más esencial

tiene derecho a la vida sin que nadie pueda privarlo de ella arbitrariamente, lo que permite apreciar una particular coincidencia entre la norma aludida y aquella que se contiene en el artículo 19, numeral primero, de nuestra Constitución... Que, previo a consignar los alcances constitucionales de la protección de la vida y de la integridad física y psíquica a que tiene derecho la persona desde su concepción, es menester ubicar la posición que tiene este derecho en la estructura de los derechos fundamentales reconocidos y asegurados por la Constitución. En este sentido, cabe observar que el derecho a la vida es, sin duda alguna, el derecho fundante de todos los demás, pues sin vida, difícilmente tiene sentido referirse a otros derechos fundamentales. Como ha señalado el Comité de Derechos Humanos de la Organización de las Naciones Unidas, en su Observación General sobre el artículo $6^{\circ}$ del Pacto Internacional sobre Derechos Civiles y Políticos, el derecho a la vida es 'el derecho supremo respecto del cual no se autoriza suspensión alguna, ni siquiera en situaciones que pongan en peligro la vida de la nación'. Ha agregado, asimismo, que 'el derecho a la vida es el más esencial de estos derechos'. La Comisión Interamericana de Derechos Humanos ha señalado, por su parte, que 'el derecho a la vida es ampliamente reconocido como el derecho supremo del ser humano y conditio sine qua non para el goce de todos los demás derechos'... Que el derecho a la vida asegurado por el artículo 19 № 1 de la Constitución, en consonancia con el artículo $3^{\circ}$ de la Declaración Universal de los Derechos Humanos; el artículo 6.1 del Pacto Internacional de Derechos Civiles y Políticos; el artículo $1^{\circ}$ de la Declaración Americana de los Derechos y Deberes del Hombre, y el artículo $4^{\circ}$ de la Convención Americana de Derechos Humanos, asegura a toda persona -incluyendo al nasciturus - el derecho a mantener la vida y a conservarla frente a los demás hombres". Rol No 740-07, sentencia 18 de abril de 2008. 
derivado de la propia naturaleza humana de la que el nasciturus participa en plenitud. En consecuencia, este Tribunal sólo puede concluir que el imperativo de proteger y promover el derecho a la vida, que se desprende del artículo $5^{\circ}$, inciso segundo, de la Constitución, en relación con el artículo 19 No 1 de la misma, conduce a declarar inconstitucionales las Normas Nacionales sobre Regulación de la Fertilidad..." Considerando Sexagésimo sexto y Sexagésimo noveno.

Estamos frente a un caso con características particulares. No se trata de una sentencia relevante desde una perspectiva estadística, aunque sí lo es desde el punto de vista material y por el alcance de la cuestión resuelta.

Se trata del primero de tres fallos donde el TC invoca el principio favor persona para resolver el juicio de constitucionalidad. De los tres casos, es en este donde la invocación del principio construido por la Corte será determinante para resolver el juicio de constitucionalidad se relaciona por tanto con la ratio decidendi del fallo. El TC reconoció que estaba ante un problema complejo. Los informes sobre los efectos del levonorgestrel en la vida del no nacido no eran concluyentes. Ante esta duda razonable es que el TC recurre a una opinión consultiva de la Corte donde se define este principio.

Será en el sistema interamericano de protección a los derechos humanos de donde se extrae una regla que permite resolver el asunto. Se trata de una cuestión de interés nacional y con efectos más allá del caso concreto por la naturaleza de la cuestión que se discute ${ }^{34}$.

\footnotetext{
34 En el ámbito de la jurisdicción de la Corte IDH, el principio pro-homine ha sido invocado, por ejemplo, en los siguientes casos: Corte IDH, Caso Acevedo Jaramillo vs. Perú, sentencia de 7 de febrero de 2006. En esta causa el representante de la demandante alegó que el Estado incumplió el artículo 26 de la Convención Americana en relación con el art. 1.1 y 2 de la misma, es decir, el deber de desarrollo progresivo de los derechos económicos, sociales y culturales, y en este sentido señaló: “(...) es necesario incorporar la normativa y jurisprudencia internacionales desarrolladas en la materia, para dotar de preciso alcance y contenido a este derecho, teniendo en cuenta la interpretación evolutiva de los instrumentos internacionales, y de conformidad con el principio pro-homine establecido en el artículo 29.b de la Convención"; Corte IDH Caso Trabajadores Cesados del Congreso vs. Perú, sentencia de 24 de noviembre de 2006. En relación con el artículo 26, los intervinientes comunes señalaron a la Corte: “(...) el Perú es Estado Parte del Pacto Internacional de Derechos Económicos, Sociales y Culturales, y del Protocolo Adicional a la Convención Americana sobre Derechos Humanos en materia de Derechos Económicos, Sociales y Culturales 'Protocolo de San Salvador', por lo que la determinación del alcance del artículo 26 de la Convención, debe hacerse teniendo en cuenta la interpretación evolutiva de los instrumentos internacionales, y de con conformidad con el principio pro-homine establecido en el artículo 29.b de la Convención; b) la obligación de progresividad está siendo violada en el presente caso, con relación al derecho a la seguridad social previsto en el artículo 45 de la Carta de la OEA"; Corte IDH, Caso Bámaca Velásquez vs. Guatemala, sentencia de 25 de noviembre de 2000. La sentencia cuenta con el voto razonado del Juez Sergio García Ramírez que señala: "En cuanto a la víctima -desde lo que originalmente se consideró víctima directa hasta ampliar su noción
} 
El principio pro-homine permite al intérprete determinar el sentido y alcance de una norma constitucional cuando éste no es claro, asimismo, puede operar como criterio para resolver sobre la amplitud o contenido esencial de un derecho fundamental, especialmente en materia de derechos económicos sociales y culturales. Su invocación en este caso resulta novedosa ya que gracias a su invocación el TC elabora su juicio de constitucionalidad en ausencia de una convicción respecto a afectación de un derecho fundamental por una norma de rango inferior ${ }^{35}$. No parece ser este el caso más adecuado para aplicar el principio.

\section{Rol No 136109 de 13 de mayo de 2009.}

Un grupo de senadores presenta un requerimiento en relación a la Ley General de Educación aún no promulgada para que el Tribunal Constitucional dicte una sentencia interpretativa donde se establezca el sentido y alcance de los artículos 25 en relación con el $8^{\circ}$ transitorio, 45 y 48 del citado proyecto de ley, con los principios y valores contenidos en la Constitución.

En este caso el TC considera que el artículo $8^{\circ}$ transitorio es constitucional y en lo demás considera no pertinente la petición principal y en definitiva rechaza el requerimiento presentado.

La invocación a la jurisprudencia de la Corte es la siguiente:

"Que por otra parte, en ejercicio de sus funciones, este Tribunal debe buscar aquella interpretación que se avenga mejor con el respeto de los derechos constitucionales.

a la víctima indirecta y potencial-, el Juez dice que este desarrollo "revela claramente el impulso tutelar del derecho internacional de los derechos humanos, que pretende llevar cada vez más lejos -en una tendencia que estimo pertinente y alentadora- la protección real de los derechos humanos. El principio favorecedor de la persona humana, que se cifra en la versión amplia de la regla pro-homine-fuente de interpretación e integración progresiva- tiene aquí una de sus más notables expresiones".

35 El "Principio pro-homine [...] tiene dos variantes principales: A) Preferencia interpretativa, según la cual el intérprete ha de preferir la interpretación que más optimice un derecho fundamental (y que se plasma en los subprincipios de favor libertatis, de protección a las víctimas o favor debilis, de prohibición de aplicación por analogía de normas restrictivas de derechos, de in dubio pro operario, de in dubio pro reo, de in dubio pro actione, etcétera). B) Preferencia de normas, de acuerdo con la cual el intérprete, si puede aplicar más de una norma al caso concreto, deberá preferir aquella que sea más favorable a la persona, con independencia del lugar que ocupe dentro de la jerarquía normativa. La preferencia de normas más favorables tiene su fundamento en el artículo 55 de la Convención Americana de Derechos Humanos". Carbonell, Miguel (2004) pp. 409-417. En el mismo sentido, señala Rodolfo Ariza: "Las condiciones para la aplicación del principio Pro Hominis supone, en primer lugar, atender a la naturaleza de los derechos que se encuentran en juego, en segundo lugar, atender los sujetos que intervienen, en tercer lugar, atender a la vigencia territorial de la fuente o norma seleccionada". Vid: http://www.circulodoxa.org/documentos/Circulo\%20Doxa\%20 $\% 20$ Hominis. Visitado el 12 de septiembre de 2008. 
Así lo ha sostenido 'en tal sentido parece ineludible tener presente el principio prohomine o favor libertatis definido en la jurisprudencia de la Corte Interamericana de Derechos Humanos de la siguiente forma: 'entre las diversas opciones que se ha de escoger la que restringe en menor escala el derecho protegido (...) debe prevalecer la norma más favorable a la persona humana’ (Opinión Consultiva 5, 1985); (Rol No 740$) ”$.

En este caso también se recurre a la doctrina, al derecho y jurisprudencia comparada para elaborar el juicio de constitucionalidad no siendo definitivo para la resolución del asunto la invocación del principio pro-homine.

5. Rol No 1484-09 de 5 de octubre de 2010.

Se trata de un requerimiento de inaplicabilidad por inconstitucionalidad presentado por la Directora del Servicio Jurídico de Vivienda y Urbanismo contra diversos preceptos del Código Procesal Penal por vulnerar los artículos $1^{\circ}$ y $5^{\circ}$ inciso segundo, 6o $19 \mathrm{No}^{\circ}$ s. 2, 3 y 26, 76, 83 de la Constitución. En este caso el TC rechaza el requerimiento y reitera principio pro-homine pero no indica sentencia de la Corte Interamericana sino que cita a Rubén Hernández del Valle cuando señala: "el citado principio junto con el pro libertatis constituyen el meollo de la doctrina de los derechos humanos y significa que el derecho debe interpretarse y aplicarse siempre de la manera que más favorezca al ser humano". Considerando Vigésimo quinto.

Para referirse al principio el TC no acude directamente a la doctrina de la Corte IDH, sino que la cita a través de un autor.

6. Rol No 1683-10 de 4 enero de 2012.

Haremos referencia a este caso, aunque queremos dejar de manifiesto que escapa a la etapa investigada por el proyecto de investigación patrocinado por Fondecyt.

En este caso el Tribunal Constitucional invocará la jurisprudencia de la Corte IDH para destacar la relevancia que ocupa en el sistema interamericano el interés superior del niño:

"Como ha sostenido la Corte Interamericana de Derechos Humanos, el interés superior del niño justifica la necesidad de que le sea dada una protección especial, en vista de su falta de madurez física y mental, debilidad o inexperiencia (OC-17/02 de 28 de agosto de 2002)". Considerando Vigésimo octavo.

Como puede verse, no se trata de una invocación novedosa ni definitiva para la resolución del fondo del caso. Esta invocación le permite al Tribunal reforzar la importancia del interés superior del niño en la resolución del asunto. 


\section{B) Los problemas que el control de convencionalidad plantea en la doctrina nacional}

La invocación de la jurisprudencia de la Corte se produce a la hora de analizar los derechos fundamentales. La jurisprudencia interamericana incide en la parte dogmática de la Constitución, que se refiere a los derechos de que son titulares las personas, de allí la importancia de su estudio.

El debate es complejo e intenso. Hemos analizado la doctrina del control de convencionalidad elaborado por la Corte y sus fundamentos normativos. Veamos enseguida las cuestiones que llevan a una parte de la doctrina nacional a ponerlo en $\mathrm{duda}^{36}$ :

1. En primer lugar, reitero, la ausencia de consenso en cuanto al valor de los tratados sobre derechos humanos ratificados y vigentes. Una suerte similar arrastrará al control de convencionalidad.

2. Aceptar como obligatoria la doctrina de la Corte Interamericana exigiría como supuesto que la jurisdicción ordinaria y constitucional adopten la tesis de que el principio de supremacía constitucional integra los derechos esenciales contenidos en tratados internacionales sobre derechos humanos ratificados y vigentes. Por tanto, dichos derechos serán también fuente superior en nuestro ordenamiento y parámetro de control de constitucionalidad-convencionalidad. Mientras no se modifique la tesis del Tribunal Constitucional que considera los tratados sometidos al principio de supremacía constitucional, ¿cómo podría actuar de otra manera? En este sentido dice la Corte IDH en Gelman 2: "En consecuencia, la pretensión de oponer el deber de los tribunales internos de realizar el control de constitucionalidad al control de convencionalidad que ejerce la Corte, es en realidad un falso dilema, pues una vez que el Estado ha ratificado el tratado internacional y

\footnotetext{
${ }^{36}$ Muchas de las críticas acá sistematizadas han sido planteadas en una serie de seminarios en los que he tenido la oportunidad de participar en 2013. Buena parte de los trabajos expuestos aún no han sido publicados, de manera que no podré citar a sus autores a riesgo de equivocarme o mal interpretar sus palabras. Dichos seminarios son: Acciones protectoras de derechos Fundamentales, organizado por la Universidad Alberto Hurtado el 19 de agosto de 2013; seminario organizado por el Centro de Estudios Constitucionales de la Universidad de Talca, Fundación Konrad Adenauer, Universidad de los Andes: La protección de los derechos humanos y fundamentales. De acuerdo a la Constitución y el derecho internacional de los derechos humanos, 10 y 11 de octubre; también el organizado por el Centro de Estudios Constitucionales de la Universidad de Talca: "Análisis jurídico de las Sentencias del Tribunal Constitucional sobre Ley de Pesca: las relaciones entre el Derecho Internacional y Constitucional a propósito del Derecho a la Consulta”, 11 y 12 de abril, y el organizado por la Facultad de Derecho de la Universidad Andrés Bello: "El diálogo entre jurisdicciones, el desarrollo del derecho público y una nueva forma de razonar", 22 al 24 de octubre de 2013.
} 
reconocido la competencia de sus órganos de control, precisamente a través de sus mecanismos constitucionales, aquéllos pasan a conformar su ordenamiento jurídico. De tal manera, el control de constitucionalidad implica necesariamente un control de convencionalidad, ejercidos de forma complementaria". Considerando 88 .

3. La doctrina del control de convencionalidad se sostiene sobre la base de la preferencia de la norma más favorable a la protección de los derechos humanos. Si existiera contradicción y fuera más garante la norma contenida en la Constitución, debiera preferirse ésta y no la que se contiene en la $\mathrm{CADH}$. Pero los tratados no deben dejar de ser cumplidos, entonces esto acarrearía la responsabilidad internacional del Estado.

El principio favor persona entrega al juez un amplio margen para determinar en cada caso concreto. ¿Cuál es la norma más favorable a la protección del derecho que se discute? No se trataría de una estructura rígida sino flexible, primará la norma más garantita, y eso es un asunto que puede variar de un caso a otro.

Desde esta perspectiva, en la cúspide del ordenamiento se encontraría la norma más favorable. El principio pro-homine es una fórmula, un canon de interpretación vacío de contenido específico. Según este planteamiento, en la parte superior de los ordenamientos no se encontraría la fuente (Constitución o tratado) sino la norma que mejor proteja el derecho. El principio de certeza y seguridad jurídica como un asunto atávico en la teoría del derecho chileno se modifica siguiendo esta tesis.

4. La ausencia de una cultura jurídica del precedente, es decir, de la creación de doctrina obligatoria por parte de los órganos superiores de justicia.

5. El seguimiento dispar de las sentencias condenatorias a Chile, por ejemplo en el caso Almonacid Arellano vs. Chile. La jurisdicción ordinaria acoge favorablemente y reabre la investigación, mientras el legislador aún no priva de efectos jurídicos al D.L. de Amnistía ni legisla sobre la imprescriptibilidad de los crímenes de guerra y de lesa humanidad ${ }^{37}$. La Corte de Apelaciones de Rancagua asume la tesis de la "cosa juzgada aparente of fraudulenta" que fue desarrollada por la misma Corte Interamericana para volver a la investigación de los hechos.

6. La ausencia de un desarrollo sistemático para la doctrina del margen de apreciación en el sistema interamericano. Se señala que no existe una doctrina clara en este sentido, a diferencia de lo que ocurre en el sistema europeo de protección

37 Agullar, Gonzalo (2013). 
a los derechos humanos donde esta doctrina se viene desarrollando ya desde hace un tiempo y permite salidas para los Estados en materias de orden valórico ${ }^{38}$.

7. Se considera, por otra parte, que la doctrina el control de convencionalidad excede el marco de los compromisos asumidos por el Estado a partir de la ratificación de la $\mathrm{CADH}$, se trataría de una obligación jurisprudencial, construida por la Corte a partir de su interpretación sin contar con texto expreso, en el que fundar el surgimiento de la obligación, a lo que se puede contrarrestar invocando el artículo 62 No 3 de la CADH que hace obligatoria su doctrina. Esta crítica no se extiende a todo el control de convencionalidad sino especialmente a lo que analizamos como la modalidad 2, esto es, que se refiere al seguimiento de la doctrina de la Corte IDH más allá del Estado directamente condenado en la sentencia.

8. La carencia del estudio y formación sistemática del Derecho Internacional de los Derechos Humanos y de la jurisprudencia de la Corte Interamericana de Derechos Humanos en la formación de abogados, jueces y operadores de las jurisdicciones ordinaria y constitucional. El Informe "Diagnóstico sobre la incorporación de los Derechos Humanos en las carreras de Derecho de Chile" concluye que sólo 5 universidades (de un total de 20) ofrecen alguna cátedra obligatoria sobre Derechos Humanos; 11 universidades desarrollan una cátedra que trata instrumentos y jurisprudencia internacionales sobre derechos humanos ${ }^{39}$.

Los argumentos expuestos resumen las razones para que en la jurisdicción constitucional y en la doctrina nacional no se desarrolle el control de convencionalidad de manera sistemática.

Para una evaluación de la actuación del TC ajena (mayoritariamente) a la doctrina de la Corte IDH, propongo introducir una distinción. Podríamos decir que la modalidad A del control de convencionalidad, que se relaciona con el seguimiento de la doctrina de la Corte en los casos donde el país ha sido condenado, encuentra un cierto grado de cumplimiento en la medida que en las sentencias examinadas el TC cita al menos: Palamara Iribarne y Claude Reyes. En el sentido de reforzar argumentos y aunque el TC no reconozca autoridad a la doctrina de la Corte que se cita en conjunto con otras referencias. Otra cosa se puede decir en relación a la jurisprudencia de la Corte Suprema, que ha dado cumplimiento

\footnotetext{
38 Sobre el margen de apreciación nacional vid: GARCíA RoCA, Javier (2011). Desde una perspectiva latinoamericana: Núnez Poblete, Manuel; Acosta Alvarado, Paola. Coordinadores (2012).

39 Vid mayores antecedentes en Informe: "Diagnóstico sobre la incorporación de los Derechos Humanos en las carreras de Derecho de Chile", elaborado por el Centro de Derechos Humanos de la Universidad de Chile y el Instituto Nacional de Derechos Humanos en 2011.
} 
a la sentencia del caso Almonacid Arellano vs. Chile y en un conjunto de casos sobre violaciones graves a los derechos humanos donde se desarrolla control de convencionalidad desde una perspectiva positiva o constructiva ${ }^{40}$. Y no se puede dejar de mencionar que la Corte de Apelaciones de Rancagua reabre el caso Almonacid una vez que Chile es condenado.

En cuanto al seguimiento sistemático de toda la doctrina de la Corte (modalidad B), en el caso del TC, sus invocaciones son bastante acotadas (Castillo Petruzzi y Opinión Consultiva 5), de manera que no podemos dar por cierto que siga la segunda modalidad propuesta. $Y$ ya si examinamos la actuación de otros poderes del Estado (recordemos que el legislador no ha dejado sin efecto el D.L. de Amnistía) así que la segunda modalidad tendría seguimiento muy dispar hoy en Chile, salvo siempre casos excepcionales.

Siguiendo la propuesta de sistematización de Sagüés ${ }^{41}$, siempre esclarecedora, podríamos afirmar que el TC intenta elaborar una interpretación armónica o constructiva entre el DI y la CADH, el TC no va a desarrollar interpretaciones donde deba optar por distintas normas, lo que va a intentar es una interpretación armónica y conforme entre el DIDH y la Constitución.

\section{CONCLUSIONES}

La polémica sobre los tratados de derechos humanos ratificados y vigentes ha sobrevivido en el tiempo más de lo que aconsejable. A estas alturas las máximas jurisdicciones del país han elaborado criterios contrapuestos. Ya volveré sobre este asunto en otros trabajos. Habría hecho falta consenso en esta cuestión. Hace falta de cara al futuro una norma que clarifique la cuestión y, a falta de ella, de criterios compartidos por ambas jurisdicciones.

El control de convencionalidad no ha tenido un seguimiento sistemático por parte del Tribunal Constitucional. Sin embargo, es destacable la importación del principio favor persona definido por la Corte IDH en sus opiniones consultivas.

Si de los pocos casos donde se ha invocado doctrina de la Corte pudiéramos sacar algunas conclusiones, podríamos decir que las dos modalidades sistematizadas por la Corte en Gelman 2 tienen algún grado de aplicación.

¿Para qué se cita? Otra distinción podríamos plantear en esta cuestión. Primero se invoca jurisprudencia de la Corte para destacar el valor o la importancia de

40 Aguilar Cavallo, Gonzalo (2013).

41 SAGỨés (2010). 
un determinado derecho (no porque se le prefiera sino seguramente porque se resuelve desechando el requerimiento).

La segunda modalidad se produce al invocar el principio favor persona para resolver un caso complejo, como el de la píldora del día después, o para fortalecer argumentos, exhortando una interpretación que se avenga mejor con la tutela de los derechos fundamentales. También para justificar la importancia de la defensa del interés superior del niño.

Lo que se importa es un criterio interpretativo que orientará a los jueces en su juicio de constitucionalidad. Si bien podemos considerar positiva esta invocación, sería conveniente que fuera una interpretación integradora y sistemática. Este es un mecanismo, como dijimos, vacío de contenido concreto, es una llave que abre distintas puertas. Por otra parte, si se aplica este principio, sería valorable que también se considerara el principio de no regresividad, de progresividad y principio precautorio en materia ambiental ${ }^{42}$.

Las conclusiones señaladas no pueden perder de vista que desde el punto de vista cuantitativo esta invocación no es relevante, salvo en lo que se refiere al principio favor persona.

Cuando se discute hoy en Chile sobre la necesidad de un cambio constitucional, la ausencia de claridad en la relación DI-Derecho interno es otra de las buenas razones para esperar una delimitación para este asunto. México, que como Chile fue tradicionalmente reticente a reconocer valor preeminente al DI, reformó su Constitución para clarificar el asunto. Eso no significa que los problemas hayan desaparecido, pero están un paso más adelante al contar con mínimos de certeza jurídica.

Mientras no se clarifique el principal problema, seguiremos asistiendo a las contradicciones del control de convencionalidad; se irán haciendo más evidentes los problemas.

Independientemente de ello, hasta ahora los tratados internacionales sobre derechos humanos han actuado como un canon de integración e interpretación de

42 Precisamente en sentido inverso resolvió el Tribunal Constitucional en la Rol No 1988-11, sentencia de 4 de agosto de 2011: “(...) como ha señalado esta Magistratura, desde el punto de vista jurídico constitucional, 'contaminación' no es cualquier impacto o alteración ambiental sino la situación que supera los parámetros ambientales establecidos... mientras no se aprueben las normas de calidad ambiental respectivas que determinen objetivamente los parámetros dentro de los cuales es admisible en el ambiente una sustancia o elemento, no corresponde hablar de contaminación, a menos que se acredite inequívocamente la presencia en el ambiente de un contaminante, en términos tales que constituya un riesgo cierto a la vida, a la salud de la población, a la conservación del ambiente o la preservación de la naturaleza, o bien que exista una situación de pública e indiscutida notoriedad de la presencia gravemente nociva en el ambiente de un contaminante". 
los derechos fundamentales. En el primer caso se ha operado a través de los derechos implícitos que el TC ya ha reconocido en varias sentencias a propósito de la tutela judicial efectiva, del derecho a la propia imagen y derecho al nombre. En el segundo caso, el DIDH ha operado como un criterio que permite reforzar los argumentos. Por su parte, la Corte Suprema ha entendido que los principios del ius cogens internacional tienen aplicación en Chile, son normas imperativas y obligatorias.

Los derechos esenciales que emanan de la naturaleza humana contenidos en esos tratados se incorporan a la Constitución material, son parte de ella y contribuyen a ampliar el catálogo de derechos cuando se reconocen derechos implícitos y también cuando se ensancha el sentido y alcance de los derechos constitucionales.

Finalmente, respecto al control de convencionalidad en cuanto a la invocación del DIDH, seguramente no quedará otro camino que el de buscar una interpretación constructiva, integradora, evitando analizar el asunto desde la primacía de una norma sobre otra, las normas se complementan, ellas configuran los derechos fundamentales. Es una alternativa temporal al actual estado de las cosas.

En cuanto a la obligatoriedad de los criterios de la Corte IDH, en mi opinión, es un asunto que requerirá de un acuerdo explícito del constituyente democrático.

\section{BiBLIOGRAFÍA CITADA}

Aguilar Cavallo, Gonzalo (2013): "Afinando las cuerdas de la especial articulación entre el Derecho Internacional de los Derechos Humanos y el Derecho Interno". Comentario de la sentencia de la Corte de Apelaciones de Rancagua en el caso del homicidio simple de Luis Almonacid Arellano, sentencia de fecha 14 de enero de 2013”, Estudios Constitucionales, Año 11 № 1.

(2012): "El control de convencionalidad en la era del constitucionalismo de los derechos. Comentario a la sentencia de la Corte Suprema de Chile en el caso denominado episodio Rudy Cárcamo Ruiz de fecha 24 de mayo de 2012". Estudios Constitucionales, Año 10 No 1.

Andrade Geywitz, Carlos (2002): Reforma de la Constitución Politica de Chile de 1989. (Editorial Jurídica de Chile, Santiago de Chile).

ARIZA, Rodolfo (2008): "Las condiciones para la aplicación del principio Pro Hominis supone, en primer lugar, atender a la naturaleza de los derechos que se encuentran en juego, en segundo lugar, atender los sujetos que intervienen, en tercer lugar, atender a la vigencia territorial de la fuente o norma seleccionada". Vid: http://www.circulodoxa.org/documentos/Circulo\%20Doxa\%20 $\% 20$ Hominis. Visitado el 12 de septiembre de 2008. 
Ávila Santa María, Ramiro (2011): El Neoconstitucionalismo transformador. El Estado y el Derecho en la Constitución de 2008. (Universidad Andina Simón Bolívar, Quito).

Biglino, Paloma (1997): "De qué hablamos en Europa cuando hablamos de Derechos Fundamentales”. Revista de Estudios Politicos (Nueva Época) (No 97 julio-septiembre). Centro de Estudios Políticos y Constitucionales, Madrid. Bobbio, Norberto (1991): El tiempo de los Derechos. (Sistema, Madrid).

Carbonell, Miguel (2011): "Los Derechos Fundamentales en América Latina: una perspectiva neoconstitucionalista". Derecho y Humanidades (No 18). (2004): "La interpretación de los derechos fundamentales". Ius et Praxis (v. 10 n. 1) Talca 2004 (Año 10 No 1): 409-417, 2004.

Carrillo Salcedo, Juan Antonio (2001): Soberanía de los Estados y Derechos Humanos en el Derecho Internacional Contemporáneo. Editorial Tecnos, Madrid.

Cea Egaña, José Luis (1997): "Los Tratados de Derechos Humanos y la Constitución Política de la República”, en Ius et Praxis (año 2 No 2), p. 81.

Correa Sutil, Jorge: "La jerarquía de los tratados internacionales de derechos humanos luego de la reforma de 2005". Revista de Derechos Humanos, link: http://www.rdh.cl/2012/07/31/jorge-correa-sutil-la-jerarquia-normativade-los-tratados-internacionales-de-derechos-humanos-luego-de-la-reformadel-2005/. Consultado 4 de noviembre de 2013.

Díez-Picazo, Luis María (2008): Sistema de Derechos Fundamentales. (Thomson Civitas, Navarra).

Ferrer Mac-Gregor, Eduardo (2011): "Interpretación conforme y control difuso de convencionalidad. El nuevo paradigma del juez Mexicano". Estudios Constitucionales (Año 9 No 2), pp. 531 y 535.

Coordinador (2012): El Control Difuso de Convencionalidad. Diálogo entre la Corte Interamericana de Derechos Humanos y los jueces nacionales. Fundación Universitaria de Derecho, Administración y Políticas, S.C., México. GaldÁmez Zelada, Liliana (2010): “Tutela judicial de graves violaciones a los derechos humanos: las actuaciones del juez y las omisiones del legislador chileno". Estudios Constitucionales (Año 8 No 2).

(2011): Impunidad y tutela judicial de graves violaciones a los derechos humanos. (Librotecnia, Santiago de Chile).

(2012): "El uso del derecho y jurisprudencia extranjera en los fallos del Tribunal Constitucional de Chile 2006-2010. Revista Chilena de Derecho. (Volumen 39 No 1). 
(2013): “Comentario jurisprudencial la consulta a los pueblos indígenas en la sentencia del Tribunal Constitucional sobre ley de pesca Roles Nos. 2387 y 2388 acumulados". Estudios Constitucionales (Volumen 11 No 1) Santiago.

García Roca, Javier; Fernandez-Sanchez, Pablo. Coordinadores (2009): "Integración Europea a través de derechos fundamentales". (Centro de Estudios Políticos y Constitucionales, Madrid).

(2011): "El margen de apreciación nacional en la interpretación del Convenio Europeo de Derechos Humanos: Soberanía e integración”. (Cizur Menor Navarra, Cuadernos Cívitas Instituto de Derecho Parlamentario. Thomson Reuters).

Hitters, Juan Carlos (2009): "Control de constitucionalidad y control de convencionalidad (comparación). Criterios fijados por la Corte Interamericana”. Estudios Constitucionales (Año 7 No 2).

"Informe Anual de la Corte Interamericana de Derechos Humanos correspondiente al ejercicio 2004, que se presenta a la Comisión de Asuntos Jurídicos y Políticos de la OEA, Washington, D.C.”, 14 de abril de 2005.

IVANSCHITZ Boudeguer, Bárbara (2013): "Un estudio sobre el cumplimiento y ejecución de las sentencias de la Corte Interamericana de Derechos Humanos por el Estado de Chile”. Estudios Constitucionales (11(1)), 275-332.

LANDA, César (2002): “Teorías de los derechos fundamentales”. Cuestiones Constitucionales (No 6), Universidad Nacional Autónoma de México.

Medina Quiroga, Cecilia (1993): Constitución, Tratados y Derechos Esenciales. Corporación Nacional de Reparación y Reconciliación, Santiago de Chile.

Mohor Aguad, Salvador (1990): "Elementos de Juicio para la Interpretación del artículo 50 inciso 2 de la Constitución de 1980", en Revista de Derecho Público (Nos. 47-48), pp. 53-193.

NASH Rojas, Claudio: "La Incorporación de los Instrumentos Internacionales de Derechos Humanos en el Ámbito Nacional: la Experiencia de Chile”. Compilación de la Facultad de Derecho de la Universidad de Chile (visitado el 10 de noviembre de 2008) disponible en formato electrónico: http://.cdh.uchile. cl/conferencias_charlas/Nash/Derechos_Humanos-Unicef.pdf.

Nikken, Pedro (1987): La Protección Internacional de los Derechos Humanos, su Desarrollo Progresivo. (Editorial Civitas, S.A., Madrid). 
Nogueira Alcalá, Humberto (2005): “Aspectos de una teoría de Derechos Fundamentales: la delimitación, regulación, garantías y limitaciones de los derechos fundamentales". Revista Ius et Praxis (Vol. 11, No 2), pp. 15-64.

(2003): Los derechos esenciales o humanos contenidos en tratados internacionales y su ubicación en el ordenamiento jurídico nacional, doctrina y jurisprudencia. Ius et Praxis, Vol. 9 No 1.

Coordinador (2013): Diálogo Judicial Multinivel y principios interpretativos favor persona y de proporcionalidad. Librotecnia Santiago de Chile.

(2012): "Los desafíos del control de convencionalidad del corpus iuris interamericano para las jurisdicciones nacionales". Boletín Mexicano de Derecho Comparado, nueva serie (año XLV No 135), septiembre-diciembre. Instituto de Investigaciones Jurídicas UNAM.

Nuñez Poblete, Manuel; Acosta Alvarado, Paola. Coordinadores (2012): “El margen de apreciación en el sistema interamericano de derechos humanos: proyecciones regionales y nacionales". (Instituto de Investigaciones Jurídicas UNAM, México).

Peces-Barba Martínez, Gregorio; llamas Cascón, A.; Fernández Liesa, C. (2001): Textos Básicos de Derechos Humanos, con estudios generales y especiales y comentarios a cada texto nacional e internacional. Ed. Aranzadi S.A., Navarra.

Pérez Luño, Antonio (1984): Derechos Humanos Estado de Derecho y Constitución, (Tecnos, Madrid.)

PinTo, Mónica (1997): El principio pro-homine. Criterios de hermenéutica y pautas para la regulación de los derechos humanos. La aplicación de los tratados de derechos humanos por los tribunales locales. Argentina, Centro de Estudios Legales y Sociales-Editorial del Puerto, Argentina. Revista Ius et Praxis (Volumen 9 Número 1), año 2003.

Rey Cantor, Ernesto (2008): Control de convencionalidad de las leyes y derechos humanos. (Porrúa. México).

Ríos, Lautaro (1998): "Jerarquía Normativa de los Tratados Internacionales sobre derechos Humanos”. Gaceta Jurídica (mayo No 215), pp. 7-14.

SAGÜÉS, Néstor Pedro (2010): "Obligaciones internacionales y control de convencionalidad”. Estudios Constitucionales Año 8 No 1.

(2010): El control de convencionalidad en el sistema interamericano y sus anticipos en el ámbito de los derechos económicos-sociales. Concordancias y diferencias con el sistema europeo. Biblioteca Jurídica Virtual del Instituto de Investigaciones Jurídicas de la UNAM. Disponible en http://biblio.juridicas. unam.mx/libros/7/3063/16.pdf. 
SAIZ Arnaiz, Alejandro (1999): La Apertura Constitucional al Derecho Internacional y Europeo de los Derechos Humanos. El artículo 10.2 de la Constitución Española. (Madrid, Consejo General del Poder Judicial).

Silva Bascuñán, Alejandro (1997): Tratado de Derecho Constitucional. Tomo IV (Santiago de Chile, Editorial Jurídica), p. 111.

UPRIMNY, Rodrigo (2000): "Bloque de constitucionalidad, derechos humanos y nuevo procedimiento penal” (consultado 10.10.2013). Disponible en http:// www.wcl.american.edu/humright/hracademy/documents/Clase1-Lectura3BloquedeConstitucionalidad.pdf.

ZúŇIGA, Francisco (2008): "Derechos humanos en la jurisprudencia del Tribunal Constitucional Chileno. Apostillas sobre Tratado y Constitución”. Revista de Derecho Político (Nos. 71-72).

\section{Jurisprudencia Tribunal Constitucional}

Rol No 309 (2000): sentencia de 4 de agosto de 2000.

Rol No 1050 (2008): sentencia de 3 de abril de 2008.

Rol No 740 (2008): sentencia de 18 de abril de 2008.

Rol No 1361 (2009): sentencia de 13 de mayo de 2009.

Rol No 567 (2010): sentencia de 2 de junio de 2010.

Rol No 1484 (2010): sentencia de 5 de octubre de 2010.

Rol No 1723-10 INA/1800-10 INA (2011): Acumulados, sentencia de 21 de junio de 2011.

Rol No 1050 (2008): sentencia de 3 de abril de 2008.

Rol No 1683 (2012): sentencia de 4 de enero de 2012.

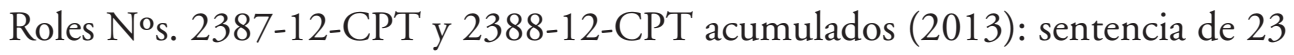
de enero de 2013.

\section{Jurisprudencia Corte Suprema}

Caso Puelman Nanco, Mariano y otros c/ Comisión Regional del Medio Ambiente de la Región de La Araucanía (2010): Recurso de protección, sentencia de 21 de enero de 2010. Rol No 1705-2009 CIV.

Rol No 517-2004 (2004): 17 de noviembre de 2004, seguida por la detención y posterior desaparición de Miguel Ángel Sandoval. 


\section{Jurisprudencia Corte Interamericana de Derechos Humanos}

Corte IDH, Caso Bámaca Velásquez vs. Guatemala (2000): sentencia de 25 de noviembre de 2000.

Corte IDH, Caso Tibi vs. Ecuador (2004): Sentencia de 7 de septiembre de 2004. (Excepciones Preliminares, Fondo, Reparaciones y Costas).

Corte IDH, Caso Acevedo Jaramillo vs. Perú (2006): Sentencia de 7 de febrero de 2006.

Corte IDH Caso Trabajadores Cesados del Congreso vs. Perú (2006): Sentencia de 24 de noviembre de 2006.

Corte IDH. Caso Palamara Iribarne vs. Chile (2005): Sentencia de 22 de noviembre de 2005.

Corte IDH. Caso Claude Reyes y otros vs. Chile (2006): Sentencia de 19 de septiembre de 2006.

Caso Almonacid Arellano vs. Chile (2006): Serie C No 154. Sentencia de 26 de septiembre de 2006.

Corte IDH, Caso Gelman vs. Uruguay (2013): En supervisión de cumplimiento de la sentencia de 20 de marzo de 2013. 